\title{
0 desafio da integralidade segundo as perspectivas da vigilância da saúde e da saúde da família
}

\author{
Integrality (comprehensiveness): \\ from the viewpoint of health care and the recent \\ proposals regarding basic assistance in Brazil
}

Carlos Eduardo Aguilera Campos 1

\footnotetext{
1 Departamento de M edicina Preventiva da Faculdade de M edicina e Núcleo de Estudos de Saúde Coletiva/UFRJ Edifício do Hospital Universitário Clementino Fraga Filho. Av. Brigadeiro Trompowsky $s / n, 50$ andar, Ala Sul, sala 33, Ilha do Fundão, 21941590 ,

Rio de Janeiro RJ. cadu@vetor.com.br
}

Abstract Multiple facets, related to the definition of policies, the structuring of knowledge and the implementing of practices in the health services, interact among themselves. This brings to light, as a final result (output), the manner in which health services are ren dered within a certain historical context (concept), and the availability or the scarcity of certain groups of activities and health services (in this country). It is essential to understand these interactions in order to be able to evaluate the course of action to be followed by health policies in Brazil. Considering, as our reference point, the Constitutional principle of integrality (comprehensiveness) of health care, and the challenges posed by its implementation, we analyze the theoretical formulations related to the concept of health care and the changes that have been implemented by the M inistry of $\mathrm{H}$ ealth in the areas of $\mathrm{B}$ asic A ssistance and Family $\mathrm{H}$ ealth (Programs). We also put on the discussion table to what extent (measures) theseformulations, propositions and in itiatives have effectively been contributing, today, to the devel opment of the U nified $\mathrm{H}$ ealth System (SU S).

Key words $\mathrm{H}$ ealth policy, $\mathrm{H}$ ealth System Organization, U nified H ealth System, Primary care
Resumo M últiplos aspectos relacionados à formulação de políticas, à construção do conhecimento e à implementação das práticas no setor saúde interagem mutuamente e têm como produto a maneira como se prestam os serviços de saúde em determinado contexto histórico ou ainda resultam na disponibilidade ou na escassez de um determinado conjunto de ações e servi ços de saúde. Compreender essas relações é fundamental para se avaliar a trajetória da política de saúde no país. Tomando-se como referência o princípio constitucional da integralidade da atenção à saúde e os desafios de sua implementação, analisam-se as formulações teóricas relacionadas ao conceito de Vigilância da Saúde eas mudanças implementadas pelo M inistério da Saúde no campo da A tenção Básica e da Saúde da Família. Busca-se ainda analisar em que medida essas proposi ções contribuem atualmente para 0 desenvolvi mento do Si stema Ú nico de Saúde.

Palavras-chave Política de saúde, O rganização do Sistema de Saúde, Sistema Ú nico de Saúde, A tenção primária 
A separação entre a medicina exclusivamente curativa e as ações essencialmente preventivas sobre 0 ambiente e sobre hábitos de vida não parece mais ter fundamentação. A melhoria da saúde da população depende, assim, em proporções desconhecidas, da qualidade do ambiente, da prosperidade geral do país e dos serviços de saúde realizados pel o sistema de tratamento. (Contandriopoulos, 1995)

\section{Introdução}

É propósito deste capítulo buscar compreender as relações que se estabelecem entre a formulação de políticas, a construção do conhecimento e a implementação das práticas no setor saúde. Quando se busca solução para um problema de saúde, quando se recorre a um médico, a um posto de saúde, a um hospital, o resultado obtido éfruto dessa complexa e imbricada relação. Os múltiplos aspectos que interagem mutuamente concorrem, por um lado, para a disponibilidade de um determinado conjunto de ações e serviços ou, por outro, para o surgimento de dificuldades de acesso aos mesmos.

Como se dá a construção coletiva e social da prática sanitária? Esteé um processo dialético e pode-se supor que estejam envolvidas instâncias distintas, ligadas às dimensões política e técnica. A primeira refere-se às condições institucionais, com o surgimento de consensos, que, através do processo político, se estruturam em princípios constitucionais, passando pel a regulamentação de dispositivos legais e seus respecti vos mecanismos de financiamento. A segunda é aquela ligada ao conhecimento que, segundo modelos teóricos, passa a dar concretude e a reger a organização e a gestão do sistema de saúde e, finalmente, a definir o conjunto de tecnologias que as ciências oferecem. Estas, uma vez combinadas, segundo sua relação de custo-efetividade, resultam em práticas de saúde e assistência voltadas para as necessidades de indivíduos, famílias e comunidades.

Devido a uma premissa fundamental trata-se de um fenômeno social e histórico essa realidade não pode ser vista como um processo linear. Assim a trajetória da política de saúde tem como ponto de partida uma construção de propósitos de grupos em luta, os quais, a cada momento, influenciam a conformação do sistema. Esse sistema resulta, portanto, dos embates e dos consensos e dissensos que ocorrem entre os grupos. E por ser histórico leva-se sempre em consideração a herança recebida, desde a existência de uma cultura institucional arraigada em unidades de saúde com diferentes conformações e espaços de prática, a refletirem uma determinada concepção histórica. Tudo isso, se não determina, ao menos condiciona os propósitos futuros.

A análise de um sistema de saúde deve iniciar-se por desvelar a lógica da sua estruturação e de seu funcionamento, bem como as articulações institu cionais que apresenta, tendo-se em mente as qualificações em relação à população abrangida, modelo assistencial implementado, e principalmente as formas de financiamento adotadas (Elias, 1996).

N osso objetivo é analisar o processo de construção e implementação da integralidade, princípio constitucional que talvez seja, nos dias de hoje, o maior desafio da saúde no Brasil. A partir daí pretendemos apresentar as propostas da vigilância da saúde como uma via para vencer este desafio.

\section{A busca de soluções para os problemas de atenção à saúde da população}

O sistema de saúde brasileiro vive há duas décadas um processo de mudança iniciado com o movimento da reforma sanitária, na década de 1980. A pós conquistas inegáveis do ponto de vista jurídico legal, tem-se atualmente como questão central a reformulação das organizações e estabeleci mentos sanitários. Tornase consenso que estes devam abandonar a lógica tradicional que regeu o seu funcionamento. Assim, busca-se criar as condições para que, de forma permanente, o sistema de saúde aproxime-se mais dos indivíduos, torne-se mais humano, solidário e, sobretudo, mais resolutivo. Princípios como territorialidade, vínculo, continuidade, planejamento local, promoção à saúde estão cada vez mais presentes nas pautas e agendas não só dos técnicos, como também dos movimentos sociais ligados ao setor. Vale ressaltar a persistência de um grave problema sanitário no país: apesar dos avanços que experimentou a saúde brasileira nas últimas décadas, graças ao processo de democratização e descentralização, entrase no século 21 com expressivos segmentos da população ainda sem dispor de acesso à aten- 
ção à saúde de al guma natureza. Essa situação é incompatível com o direito constitucional.

A tender às necessidades e aos anseios da população foi a motivação básica para a criação do Sistema Ú nico de Saúde. As dificuldades não residiam apenas no arcabouço institucional, isto é, no conjunto de leis existentes à época, que dava prioridade ao modelo em que a atenção previdenciária era o principal foco da política pública. Há que se considerar entre as heranças recebidas pelo SU S, em décadas de estruturação do setor saúde, a cultura organizacional, os diversos interesses financeiros e comerciai s incompatíveis com o interesse público, euma prática médica fragmentada e descontextualizada da realidade dos cidadãos. Esses padrões institucionais conformaram um conjunto de pressupostos e valores de difícil, e lenta, transformação, a despeito de existirem propósitos políticos de mudança da parte da maioria dos atores sociais envolvidos no setor. Daí se considerar, atualmente, que o SU S estaria ainda em gestação, especialmente por existir há pouco mais de uma década. Em se tratando do setor saúde porém, é justificável a impaciência verificada com relação à lentidão com que se dão as mudanças, frente às urgências da população por mais saúde.

M esmo quando se consideram dificuldades como as acima descritas, vários progressos têm sido alcançados. Um dos pontos a destacar é o desenvolvimento da atenção primária à saúde, formada por uma rede que se consolidou em todo o país. Centros e postos de saúde, os estabelecimentos sanitários destinados a prestar serviços bási cos à população, experimentaram um crescimento bastante expressivo, tanto em número absoluto quanto em produção de serviços e aumento de cobertura assistencial, especialmente em áreas antes desassi stidas. Criadas na década de 1930, essas unidades se multiplicaram por todo o país, e se expandiram, de forma acelerada, a partir dos anos 80. Esse foi um dos ganhos oriundos do processo de descentralização da saúde previdenciária e da subseqüente municipal ização do sistema de saúde brasileiro.

Essa rede básica ampliou sua oferta de serviços segundo dois eixos fundamentais: a prestação de atendimento médico ambulatorial nas especialidades básicas ( pediatria, ginecologia e obstetrícia, clínica médica) e a oferta de ações de caráter preventivo, segundo a lógica da programação em saúde. Esta pode ser definida como: o conjunto de práticas que, a partir de um referencial epidemiológico, toma como seu objeto de intervenção a saúde e a doença no coletivo, utilizando como instrumento de intervenção diversas ati vidades que são articuladas e organizadas no sentido de produzirem um efeito sobre a saúde no plano coletivo (Sala, 1993).

Os programas de saúde buscam, em outras palavras, com base em prioridades, eleitas segundo critérios como magnitude, vulnerabilidade, transcendência, combinar tecnologias e intervenções de caráter clínico-epidemiológicas cal cadas em medidas de impacto, eficácia, efetividade e eficiência comprovadas. Essas ações são a parte mais visível do trabal ho das unidades básicas. É inegável terem alcançado progressos, que se refletem em mel horias de determinados indicadores sanitários. Além disso, em diversos setores sociais, existe o apoio necessário à sua continuidade. Entre as ações, destacam-se os programas de combate à desnutrição eà diarréia na infância, de prevenção da Aids, de imunizações, de prevenção do câncer de mama, do aleitamento materno, do controle da hipertensão, de diabetes, etc.

Ainda assim não se pode afirmar que 0 sistema como um todo sofreu as transformações substanciais esperadas, nem que tenha correspondido aos anseios da população. $M$ uitos problemas ainda persistem. Com relação aos programas de saúde, a opção feita por operá-los tomando por base as especialidades de cada área acarretou a fragmentação do trabalho desenvolvido nas unidades básicas. Geralmente, onde existe o recurso disponível, o cardiologista atua no programa de controle da hipertensão; o pneumologista, no programa de controle da tuberculose; o dermatologista, no programa de controle da hanseníase e assi $m$ por diante. 0 s impasses decorrentes dessa forma de atuar são evidentes. Reproduz-se um atendimento especializado, muito próprio do ambiente hospitalar, comprometendo as premissas da atenção primária à saúde. Além disso, as dificuldades em se dotar cada um dos postos de saúde de recursos adequados é evidente neste modelo. De tal forma que, por exemplo, postos possuem atendimento de pediatria, às segundas e sextas pela manhã, de clínica médica; às terças e quintas, de ginecologia e pré-natal; às quartas, etc.

Contribuiu ainda para aprofundar essa 
fragmentação as medidas, sempre urgentes, de estender a cobertura assistencial, lotandose profissionais para realizar, nas unidades básicas, consultas médicas ambulatoriais sem nenhum planejamento ou estudos para adequá-las às necessidades locais. Estas foram, freqüentemente, organizadas na modalidade de pronto atendimento, sempre em número insuficiente e sem nenhum vínculo entre as equipes e os indivíduos. Assim realizou-se um trabal ho paral elo à lógica da programação em saúde, buscando responder às demandas dos indivíduos que não eram atendidos pelas ações programáticas. A esses problemas acrescenta-se, ainda, a falta de treinamento dos profissionais para trabal har segundo os princípios da atenção primária à saúde, e a baixa remuneração. Em conseqüência, ao invés do espaço comunitário em que se busca a integração da ação curativa com as de promoção e de prevenção à saúde, é comum a existência de filas de pacientes, desde a madruga$\mathrm{da}$, em busca de "uma ficha" para atendimento com um especialista. Parece haver, nesses casos, a importação da lógica dos serviços de emergência e de urgência ao trabalho da atenção primária à saúde.

0 trabalho nos estabelecimentos de saúde e entre el es, na U nidade Básica, é organizado, tradicionalmente, de forma extremamente parcelada. Em eixo verticalizado, organiza-se o trabalho do médico e entre estes, o de cada especialidade médica. Assim, sucessivamente, em colunas verticais vai se organizando o trabalho de outros profissionais. Essa divisão do trabalho se dá, de um lado pela consolidação nos serviços de saúde das corporações profissionais, e por outro, no caso dos médicos, pela especialização do saber e, con seqüentemente, do trabalho em saúde. A organização parcelar do trabalho fixa os trabalhadores em uma determinada etapa do projeto terapêutico. A superespecialização, o trabalho fracionado, fazem com que o profissional de saúde se aliene do próprio objeto de trabalho. Desta forma, ficam os trabalhadores sem interação com 0 produto final da sua atividade laboral, mesmo que tenham dele participado, pontualmente. Como não há interação, não haverá compromisso com o resultado do seu trabalho (Franco et al., 1997).

Segundo M ehry, além da segmentação, há ainda o problema da ati tude do médico, cujo trabalho é marcado pelo distanciamento com relação aos interesses dos usuários, pelo iso- lamento com relação aos outros trabalhadores da saúde e pelo predomínio de modalidades de intervenção centradas nas tecnologias duras, isto é, por um modelo assistencial voltado para a produção de ações baseadas em máquinas e procedimentos: 0 trabalho médico orientado por este modelo se isola dos outros trabalhos em saúde, vai se especializando à introdução de cada novo tipo de associação entre procedimentos e máquinas, vai necessitando de uma autonomia que o separa das outras modalidades de abordagem em saúde, e alimenta-se de uma organização corporativa poderosa, voltada, eticamente, para si mesma. Desta maneira, estas intenções que comandam o trabalho médico comprometido com a produção de procedimentos estão articuladas com um exercício da autonomia no trabalho clínico totalmente voltado para interesses privados estranhos aos dos usuários, e isolado de um trabalho mais coletivo no interior das equipes de saúde, fechado e protegi do no espaço físico dos consultórios, em nome de uma eficácia e de uma ética que não se sustentam em nenhum dado objetivo, em termos da produção da saúde (M erhy, 1997).

$M$ uitas dessas distorções não acontecem apenas no Brasil. Em vários países, o dilema com que se deparam os sistemas nacionais de saúde se circunscreve entre a necessi dade de tornar universal a assi stência médica de qualidade e a constante busca de contenção do gasto público e privado no setor. Pois o modelo atual de atenção médica leva, inexoravelmente, ao problema do aumento sempre crescente de custos (Labra e Buss, 1995). O mito da imortalidade e do poder mágico da medicina se mantém no inconsciente coletivo, a despeito de todas as evidências ao contrário. O leque de opções por novas tecnologias e produtos, sempre em evolução, estimula um consumo individual sem precedentes, de forma acrítica, sem que haja uma comprovação clara de sua efetividade com relação a procedimentos anteriormente adotados.

Tanto a ampliação de cobertura da atenção primária à saúde quanto a estratégia de melhorar a relação custo/efetividade, contida na lógica da programação em saúde, são tentativas de resposta a esse dilema. D e fato, em que pese a heterogeneidade do sistema de saúde brasileiro, composto de uma complexa mistura pública/ privada, ganha a hegemonia, na estratégia de estruturação do SUS, a atenção primária à saúde, com o fortalecimento e 
a disseminação da rede básica, de responsabilidade do poder municipal. E muitas vezes se desconfia ser essa forma de atuação do setor público uma política de focalização, uma espécie de cesta básica sanitária, destinada a atender, como mais um programa social, os grupos mais carentes e desvalidos da população.

É importante esclarecer que dar prioridade à prevenção não é, necessariamente, uma estratégia de conten ção de custos. Pois não se pode descuidar do atendimento das demais necessidades de saúde, nos níveis mais complexos do sistema, quando se tem em mente o cumprimento dos objetivos e pressupostos do Sistema Ú nico de Saúde. Estes são, segundo a Lei Orgânica da Saúde, assegurar o acesso universal e igualitário a todos os níveis de assistência e prestar ações e serviços preventivos ecurativos, individuais e coletivos.

Recentemente teveinício um debate entre os gestores federais e estaduais, sobre a regionalização do sistema de saúde. E em documentos relati vos à regi onalização lê-se que a expansão da rede básica e o processo de descentralização não podem prescindir de mecanismos que dêem aos municípios a capacidade de oferecer ações de caráter abrangente, segundo os diversos níveis de assistência capazes de atender em todas as demandas. Há urgência de se corrigir a tendência a uma assistência exclusivamente voltada para a atenção básica, em virtude da pequena capacidade, dos municípios, de proverem os investimentos necessários para se prestar serviços de assistência hospitalar, ou serviços especializados. Conclui-se, assim, haver necessidade de se construírem redes articuladas segundo planos regionais, sob risco de um processo de desintegração organizacional e da competi ção entre órgãos gestores e da conseqüente atomização do SU S em milhares de sistemas locais, in eficientes, iníquos e não resolutivos (M inistério da Saúde, 2001).

Essa proposta de regionalização busca assim integrar as iniciativas e os recursos disponíveis em cada município, organizando pólos de referência para os atendimentos de maior complexidade ou para procedimentos de alto custo. Assim possibilita-se uma oferta mais equânime dos serviços considerados de referência. Busca-se com isso evitar que os sistemas locais padeçam das dificuldades de encaminhamento aos níveis mais complexos do sistema. Esta proposta vem ao encontro das iniciativas de formação de consórcios intermunicipais, constituídos no país ao longo daúltima década.

\section{A integralidade como princípio norteador do sistema de saúde}

O conceito de integralidadeéum dos pilares a sustentar a criação do Sistema Ú nico de Saúde. Princípio consagrado pela Constituição de 1988, seu cumprimento pode contribuir muito para garantir a qualidade da atenção à saúde.

Em primeiro lugar prevê-se nesse conceito que, de forma articulada, sejam ofertadas ações de promoção da saúde, prevenção dos fatores de risco, assistência aos danos e reabilitação - segundo a dinâmica do processo saúde-doença. É importante ressal tar que os diferentes momentos da evolução da doença e as respectivas medidas a serem tomadas seguem o modelo da história natural da doença, teoria consagrada por W hite na década de 1960. Segundo essa teoria, o estágio em que se encontra determinado agravo à saú de está diretamente referido a níveis de intervenção segundo conhecimentos e tecnologias disponíveis para atuação em âmbitos individuais e coletivos. Estes precisam estar articuladose integrados em todos os espaços organizacionais do sistema de saúde.

Quando se considera a abrangência do conceito de integralidade, tal como descrito acima, pode parecer uma contradição a definição transcrita no texto constitucional: A ten dimento integral, com prioridade para as atividades preventivas, sem prejuízo dos serviços assistenciais (Brasil, 1988).

A prioridade atribuída à preven ção tem, nesse particular, uma forte conotação política, e leva em consideração a trajetória da atenção à saúde no Brasil. 0 texto constitucional busca resgatar a enorme dívida do sistema de saúde diante da preven ção das doenças da população brasileira. Assim o fez para dar um sentido de mudança à forma como, historicamente, se desenvolveu a assistência à saúde no Brasil. As organizações do setor sempre dividiram suas ações em médico-assistenciais e preventivas e, por sua vez, tiveram pesos distintos no sistema, e foram oferecidas de maneira desigual. Hoje busca-se oferecer assistência integral através de uma maior articulação das práticas e tecnologias 
relativas ao conhecimento clínico e epidemiológico.

N ote-se ainda a ausência, no texto constitucional, de referências à promoção da saúde. I sso pode ser atribuído à pouca difusão do conceito à época dos trabalhos da Assembléia Nacional Constituinte. A ênfase dada à promoção da saúde é portanto mais recente e não foi sequer citada quando da votação da Constituição.

O primeiro desafio na busca do atendimento integral é reestruturar a forma como os distintos estabel ecimentos e organizações do setor saú de trabal ham ainda até os dias de hoje. A mudança das práticas de saúde deve ocorrer em dois níveis. 0 primeiro, institucional, da organização e articulação dos serviços de saúde. 0 segundo, das práticas dos profissionais de saúde, no qual o médico é o sujeito, ator primordial, determinante do processo de estruturação das práticas integrais à saúde.

Os saberes e práticas a conformarem 0 campo da epidemiologia se estruturaram em organizações que desenvolveram, tradicionalmente, ações de vigilância epidemiológica, vigilância sanitária e programas de saúde pública. Desde o início do século passado, esses estabelecimentos foram responsáveis pelo trabal ho no campo da saúde coletiva. E atuaram, predominantemente, sobre os problemas das coletividades, em áreas como a da educação em saúde, o controle de doenças contagiosas e de vetores, o saneamento, as intervenções so bre o meio ambiente e, mais recentemente, a prevenção de fatores de risco e a promoção à saúde. 0 s centros e postos de saúde foram a parte mais visível da ação.

Já a assistência clínica se organizou, notadamente a partir da década de 1950, em hospitais da previdência social voltados para a atenção aos trabalhadores do mercado formal. Sua tarefa primordial era 0 aten dimento médico, especializado e individual, em termos de tratamento e reabilitação.

Só no final da década de 1970, se iniciaram esforços, ainda que tímidos, para a integração do sistema dualista. Existiu, portanto, uma histórica dicotomia entre as ações de caráter hospitalar e curativo, de um lado, e as ações do campo da saúde coletiva, de cunho mais preventivo e coletivo, de outro. E essa divisão não se deu apenas nas estruturas administrativas.

A assistência médica hospitalar contava com vultosos recursos da máquina previdenciária, enquanto a saúde pública era financiada por escassos recursos do Tesouro $\mathrm{N}$ acional ou fomentos oriundos de organismos internacionais. Assim, o Sistema Ú nico de Saúde herdou uma rede de saúde que representa um desafio para a assistência integral. Em que pese 0 grande número de centros e postos de saúde em nosso país, estes sofreram com as restrições orçamentárias, as soluções de continuidade na reposição de recursos humanos e sempre estiveram em segundo plano diante da rede hospitalar. $\mathrm{Nem}$ ao menos havia um sistema de financiamento para as ações municipais que não estivessem ligadas ao aten dimento e aos procedimentos médico-individuais. 0 financiamento por produção de consultas, exames, internações limitava, decisivamente, a expansão da atividade preventiva e coletiva. 0 país dispõe de uma rede de saúde muito mais centrada na produção de procedimentos médicos e diagnósticos, pouco integrada e mal distribuída, segundo as regiões. 0 processo de municipalização da saúde brasileira abriu, porém, novas perspectivas nesse campo, e é fruto da participação das comunidades e dos movimentos sociais. E, como tem sido chamada atualmente, a atenção básica passou a ser mais discutida e priorizada pelos gestores da área.

Leis e decretos mais recentes, relativos a novas formas de financiamento e de gestão do sistema de saúde brasileiro, mel horaram as condições para que o gestor municipal possa cumprir o preceito constitucional da integralidade. As mudanças na lógica de financiamento se consubstanciaram na promulgação da N orma O peracional Básica-96. A exigência de haver setores responsáveis por cada ação e atividades de controle e avaliação foram requisitos para a habilitação de municípios em "gestão plena do sistema de saúde". As resoluções concernentes à implantação, por um lado, do Piso Assistencial Básico (PAB), em seus componentes fixo e variável e, por outro, da Programação Pactuada da Epidemiologia e Controle de Doenças (PPI-ECD) foram os principais mecanismos dessa mudança.

Se bem que tardiamente, e ainda sem ter alcançado as condições de garantia plena da atenção integral, essa norma operacional básica permite que sistemas locais de saúde passem a dispor de recursos desvinculados da realização de procedimentos diagnósticose terapêuticos. O s sistemas passam a receber 
recursos globais, segundo aspectos como perfil populacional, indicadores sanitários e epidemiológicos, desigual dades regionais, metas de cobertura, desempenho, etc. Passou-se a exi gir que o gestor planeje ações voltadas para a melhoria das condições de saúde, segundo a evolução de indicadores sanitários e epidemiológicos. Assim, cabe ao gestor municipal pactuar, por exemplo, a redução da prevalência de determinadas doenças ou o aumento da cobertura vacinal ou pré-natal. Buscase, em suma, estabelecer um sistema de financiamento centrado mais em metas de impacto epidemiológico do que na produção de consultas ou internações.

0 processo de pactuação de metas de cobertura e desempenho e de repasse financeiro exige a participação dos conselhos municipais de Saúde. Esses conselhos devem referendar e registrar em ata os compromissos assumidos pelos gestores municipais. Dessa forma existe uma mai or transparência das ações do governo no setor. Em seguida os pleitos muni- cipais são submetidos à instância estadual; analisad os (aprovad os ou não) na Comissão Intergestora Bipartite, que reúne o consel ho de gestores munici pais e a secretaria de saúde do estado. 0 mesmo processo se dá no nível federal, na Comissão Intergestora Tripartite. $\mathrm{N}$ os exemplos que se seguem, apresentamos alguns compromissos firmados por gestores municipais do Estado do Rio de Janeiro para o recebimento de recursos do Piso de Atenção Bási ca e da Programação Pactuada e I ntegrada da Epidemiologia e Controle de Doenças. Como já mencionado, ao invés de se firmarem convênios com municípios para a produção de consultas, exames ou internações, repassam-se recursos, fundo a fundo, mediante a assi natura de um pacto. Segundo esse pacto, várias metas de desempen ho do sistema municipal serão avaliadas por meio da análise da melhoria de indicadores relacionados, direta ou indiretamente, à estrutura, ao processo ou ao resultado das ações de saúde, geralmente voltados para a saúde coletiva.

\section{Quadro 1}

M etas pactuadas pelos municípios do Estado do Rio de Janeiro - 2000

Piso da Atenção Básica- PAB

Atingir e/ ou manter cobertura de $95 \%$ para o esquema vacinal de rotina;

Reduzir o número de internações por tétano neonatal, por tétano, sarampo e difteria;

Reduzir o número de óbitos em menores de 1 ano;

Oferecer, no mínimo, quatro consultas de pré-natal por gestação;

O rganizar ações de prevenção de gravidez na adolescência;

Reduzir as internações por infecções respiratórias agudas em crianças eidosos;

Reduzir as internações por desidratação aguda em menores de cinco anos;

Reduzir as internações por AVC, infarto e complicações da diabetes em adultos;

Alcançar $95 \%$ dos animais domésticos com a vacinação anti-rábica.

Fonte: SES-RJ, 1999

\section{Quadro 2}

M etas pactuadas pelos municípios do Estado do Rio de Janeiro - 2000

Programação Pactuada el ntegrada - Epidemiologia e Controle de D oenças - PPI-ECD

D etectar 1,3 casos de hanseníase por 10.000 habitantes;

Cadastrar $100 \%$ das fontes de abastecimento deágua;

Investigar $100 \%$ das notificações compulsórias de tuberculose, hepatite, meningite;

Vacinar contra o sarampo 95\% da população menor de 1 ano;

I mplantar o monitoramento das doenças diarréicas agudas (M DDA);

Implantar o programa de tuberculose. Detectar 100/100.000 hab.;

Implantar e executar as ações pactuadas no PEAa (controle da dengue). 
Quadro 3

Recursos federais do SUS/T ransferências em 1999

Municípios do Rio de Janeiro

Atenção Básica/PPI-ECD/Controle deVetores

\begin{tabular}{lccc}
\hline Município & População & Transferência & Valor per capita \\
\hline São José de Ubá & 5.862 & $01.534,54$ & 34,38 \\
Areal & 9.596 & $295.113,69$ & 30,75 \\
Sumidouro & 14.118 & $424.105,52$ & 30,71 \\
Pinheiral & 19.958 & $408.919,87$ & 20,49 \\
São João da Barra & 29.861 & $731.667,31$ & 24,50 \\
Rio Bonito & 47.670 & $888.414,21$ & 18,64 \\
Maricá & 68.728 & $1.145 .711,30$ & 16,67 \\
Angra dosReis & 98.229 & $1.938 .010,52$ & 19,73 \\
Nova Friburgo & 171.154 & $2.169 .871,51$ & 12,65 \\
Petrópolis & 282.182 & $4.252 .923,04$ & 15,07 \\
Niterói & 462.884 & $7.641 .005,01$ & 16,51 \\
Duque deCaxias & 758.738 & $11.415 .824,44$ & 15,09 \\
Rio dejaneiro & 5.613 .897 & $82.971 .512,66$ & 14,78 \\
\hline
\end{tabular}

Fonte: Joyce Schramm. SES-RJ, 2000

Nos quadros 1 e 2 buscou-se destacar algumas das metas, de um total de 132. E, assim, épossível perceber a importância do processo de compromisso mútuo entre os diversos níveis de governo. Para definir os números, toma-se a base histórica e o nível atual da incidência e da prevalência, ou a situação dos programas em execução no município. Cabe ao nível estadual o acompanhamento ea assessoria técnica para que os municípios possam desempenhar suas tar efas e al cançar êxito.

0 quadro 3 ilustra o volume total de repasse de recursos ao longo do ano de 1999, a municípios do Estado do Rio, segundo as populações dos mesmos. Incluiu-se, além do PAB e da PPI-ECD, os valores transferidos para 0 combate à dengue. Esteúltimo valor varia em decorrência do grau de infestação de cada município. Osvalores, apesar de apresentarem uma evolução crescente, ainda não chegam a $10 \%$ dos recursos destinados pelo SUS à assistência médica hospitalar e ambulatorial. M as, como os valores destinad os à atenção básica e ao controle de doenças sempre foram inferiores a $2 \%$, podemos considerar um avanço. N ão estão incluídos percentuais, a serem obrigatoriamente aplicad os pel os estados e municípios, de recursos de seus respectivos orçamentos fiscais. Estes percentuais deverão alcançar, segundo a nova legislação, cerca de $30 \%$ do repasse federal. Dessa forma, 0 financiamento à saúde passa a envolver recursos dos três níveis de governo.

0 quadro 3 revela uma preocupação dos gestores federal, estadual e municipal em promover um mecanismo compensatório em favor de municípios menores, de forma a lhes destinar ao menos o montante de recursosindispensável para a execução do controle de doenças (PPI-ECD). Isso significa prover municípios menores com um adicional de recursos e se revela quando se observa a variação dos valores per capita, que receberam valores maiores. Como já referido, o grau de infestação pelo A edes aegypti também determinou algumas diferenças no valor per capita. Nova Friburgo e Petrópolis, por exemplo, receberam repasses menores dessa fonte.

Como já descrito anteriormente, o sistema de financiamento dos recursos oriundos do PAB, especialmente aqueles previstos na parte variável e da PPI-ECD, induz a uma reorganização da forma de atenção. E contempla com mais recursos os municípios que implantarem formas de assistência inovadoras tais como as equipes de saúde da família, a assistência ao desnutrido, a farmácia básica, os centros de controle de zoonoses, etc. Essa nova metodologia de repasse de recursos exige uma maior participação de gestores e comunidades no planejamento e na avaliação das ações de saúde municipais. E contribui para ampliar e qualificar, através dos conse- 
Ihos municipais de Saúde, o controle social exercido por estes fóruns, e para conformar, através desses consel hos, o interesse coletivo pela garantia de atenção integral .

U m segundo aspecto ligado à integralidade refere-se à garantia de acesso, do indivíduo, aos diversos níveis de atenção, primário, secundário eterciário. A idéia de que níveis de complexidade estejam relacionados diretamente, com menor ou maior grau de especialização, leva à idéia de a atenção primária à saúde apresentar menor grau de dificuldade ou exigir menor grau de conhecimento ou habilitação. Isso é um equívoco, pois o nível de complexidade mais básico do sistema está relacionado com a necessidade de conhecimentos mais abrangentes, enquanto os níveis secundário e terciário são mais específicos ou parcelados/especializados, e usam intensivamente procedimentos baseados em aparelhos e exames. No nível primário são utilizadas intervenções com enfoque preventivo, comunitário e coletivo, destinadas a atender aos problemas mais comuns da população. Por envolverem determinação múltipla, necessitam de um conhecimento muito diversificado dos profissionais, pois, nesse nível, trabal ha-se segundo a lógica da multicausal idade.

Ainda segundo o conceito de integralidade, as pessoas são encaradas como sujeitos. A atenção deve ser totalizadora e levar em conta as dimensões biológica, psicológica e social. Este modo de enten der e abordar o indivíduo baseia-se na teoria holística, integral, segundo a qual o homem é um ser indivisível enão pode ser explicado pelos seus componentes, físico, psicológico ou social, considerados separadamente.

A garantia do princípio da integralidade, em suma, implica dotar o sistema de condições relacionadas às diversas fases da atenção à saú de, ao processo de cuidar, ao relacionamento do profissional de saúde com os pacientes. Indivíduos e coletividades devem dispor de um atendimento organizado, diversificado e humano. Esse princípio, portanto, não exclui nenhuma das possibilidades de se promover, prevenir, restaurar a saúde e reabilitar os indivíduos.

Para se alcançar a integralidade no sistema de saú de faz-se necessário que os gestores municipais, estaduais e federais passem a dar prioridade a este princípio. I mplica perguntar se, na prática cotidiana da gestão e da operação do sistema de saúde, seus pressupostos têm sido respeitados. Existem diversos mecanismos os quais o gestor pode lançar mão para que este princípio seja cumprido. N esse sentido, Giovanella (2000) buscou sistematizar e apresentar uma metodologia inovadora para avaliar se os sistemas municipais de saúde são mais, ou menos, integrais. Como ponto inicial esta forma de organizar o sistema depende da vontade política, ao se definirem prioridades, e também de mudanças organizacionais e da forma de gestão do sistema de atenção. Em suma, os sistemas integrais de saúde deveriam atender a algumas premissas básicas, quais sejam: a primazia das ações de promoção e prevenção; a garantia de atenção nos três níveis de complexidade da assistência médica; a articulação da ações de promoção, prevenção, cura e recuperação; a abordagem integral do indivíduo efamílias (Giovanella, 2000).

\section{Eixos reestruturantes do SUS: a vigilância da saúde e a estratégia da saúde da família}

Para al cançar êxito em seus objetivos, uma determinada política de saúde necessita del eis emecanismos degestão apropriados. A forma como os estabelecimentos e organizações são concebidose organizam suas práticas influi decisivamentena satisfação dos usuários eno impacto das ações sobre a saúde dos indivíduos. Sem mudanças nos pressupostos e paradigmas a nortearem o modelo assistencial brasileiro, não se pode esperar resposta sati ffatória aos problemas que se apresentam no dia-a-dia da interação da população com os serviços de saúde. A forma como se organiza a sociedade esuas práticas sociaisé, por si só, determinante para a definição dos problemas de saúde edo modo de solucioná-los. Não énenhuma surpresa, portanto, constatar-sea hegemonia deum sistema voltado para aten der, quase que exclusivamente, demandas individuais, sendo a assistência médica o principal recurso tecnológico colocado à disposição dos indivíduos, em escal as de acesso progressivas e de acordo com a capacidade de compra dos diver sos segmentos da população. Sea integralidade pressupõe atuar sobreos determinantes eos riscos deadoecimento, quetipo de gestão sanitária poderia superar as restrições apontadas acima? Como proposta no campo teórico metodológico a vigilância da saúdeconstituise um esforço para integrar a atuação do setor saúde sobreas várias dimen sões do processo saú- 
de-doença, especialmente do ponto de vista da sua determinação social. A partir daí busca desenvolver novas propostas de operacionalização dos sistemas de saúde, deforma a se respeitar uma visão que se pretendemais totalizadora.

0 primeiro desafio a ser superado refere-seà dicotomia das ações dos setores envolvidos na assistência à saúde. 0 modelo de vigilância da saúdepode ser considerado um eixo reestruturante da maneira de se agir em saúde. Seguindo esse modelo, os problemas de saúde passam a ser analisados e enfrentados de forma integrada, por setores quehistoricamentetêm trabal hado de maneira dicotomizada. Consideram-se os determinantes sociais, os riscos ambientais, epidemiológi cos e sanitários associados e os desdobramentos, em termos dedoença. Essenovo olhar sobrea saúde leva em conta os múltiplos fatores envolvidosna gênese, no desenvolvimento ena perpetuação dos problemas. Propõeainda o envolvimento detodos os setores inseridos naquela realidadee vêo indivíduo ea comunidade como o sujeito do processo.

A vigilância da saúdetem no princípio deterritorialidade sua principal premissa. 0 trabalho em saúde deve estar imerso no contexto territorial. Assim consegue-se definir problemas, eum conjunto de prioridades, bem como obter os recursos para atender às necessidades de saúde da comunidade considerando cada situação específica. 0 território éentendido como o espaço onde vivem grupos sociais, suas relações econdições de subsistência, detrabalho, de renda, dehabitação, de acesso à educação eo seu saber preexistente, como parte do meio ambiente, possuidor deuma cultura, de concepções sobre saúde e doença, de família, de sociedade, etc. Além de mudanças teóricas e metodológicas que permitem a ampliação detecnologias para fazer frente aos problemas de saúde, a vigilância da saúde propõe que os agentes sociais sejam os responsáveis pelo processo de definição de problemas e pelo encaminhamento das soluções. 0 indivíduo éo objetivo final da vigilância da saúde, mas deveser considerado parte da família, da comunidade, do sistema social, do ambiente. Qualquer ação de saúde que se pretenda realizar deverá incidir sobreesteconjunto. Um indivíduo não existesozinho, isolado. Todo homem é resultado das relações que estabelece. 0 indivíduo autônomo, independente, éuma abstração ideológica, ligada a uma determinada visão de mundo. É preciso compreender que meIhorar a qualidade de vida, promover a saúdede um indivíduo implica agir no contexto em queele seinsere, no espaço em queelevive.
Parafacilitar a compreensão das múltiplas dimensões da proposta da vigilância da saúde, iremos abordar esta proposta segundo três níveis, quais sejam, os determinantes do processo saúdedoença, os riscose os danos à saúde. U tiliza-seesta estratégia apenas para fins didáticos, já queentender a indissociabilidade da atuação sanitária é fundamental para as mudanças propostas. Utiliza-se como referencial teórico o modelo proposto por Teixeira, Paim eVilasbôas (1998).

A atuação segundo as múltiplas e complexas determinações do processo saúde-doença inseresenas formulaçõesrecentes, agrupadas sob o conceito da promoção da saúde. Apesar de promissora, a proposta de promover saúde é, ao mesmo tempo, desafiadora ecomplexa, tanto do ponto de vista político quanto do ponto de vista técnico. M uitas de suas ações envolvem instâncias quese encontram fora do setor saúde. A promoção da saúde implica o estabelecimento de agendas públicas com a partici pação de diversos atores, envolvendo pessoas e comunidades para sealcançar mais saúde euma melhor qualidade de vida. Para se dimensionar a complexidade desse conceito pode-se utilizar a seguinte situação hipotética. Suponha-se que uma determinada secretaria de saúde municipal lance o seguintedesafio à socie dadelocal: na próxima década propomos elevar a vida média de nossos moradores em cinco anos. É sabido queesse tipo de proposta depende de inúmeras variáveis, tendo a secretaria de saúde uma responsabilidade apenas limitada para o seu alcance. M ais anos devida para todos vai certamente depender demúltiplas estratégias, iniciando-se pela própria consciência dosindivíduos efamílias de queisto é possível edesejável. 0 setor saúdenão pode, de formaisolada, al cançar esta meta. $\mathrm{M}$ as, ao mesmo tempo, deveexercer um papel de liderança, decisiva para estabelecer esta agenda. U ma atitude propositiva, contribuindo para criar este cenário. Cabe ao setor aval izar o tipo de utopia, comprovando ser possível aquilo quea sociedadetem dificuldadeem vislumbrar. Senessedeterminado município pessoas morrem vítimas de atropelamentos ou de leptospirose, caberá salientar para todos os indivíduos efamílias que o quadro não éinexorável equepodeser superado. Não éutopia, esim uma possibilidadereal. Isso já foi alcançado em outras sociedades e países. Outras condições que possam ser enfrentadas a médio e longo prazos devem ser apontadas. No exemplo citado há ainda um outro aspecto a ser mencionado. Um município não éuma ilha, mas estáinserido em um contexto estadual, federal, continental, etc. Várias políticas públicas e mobilizações 
sociais necessitam, para o seu sucesso, de uma abrangência e compromissos que extrapolam 0 território municipal. É necessário que se discutam novas formas de relações sociais, de organizações eestabelecimentos que atendam melhor às necessidades de saúde e de qual idade de vida dosidosos, das crianças, ou ainda, dos portadores de deficiência, dos trabalhadores enão só a assistênciaàs suas doenças.

A la Conferência Internacional sobrePromoção à Saúde, realizada em Ottawa, em 1986, emitiu a Carta de Ottawa, assim definindo a promoção à saúde: A promoção à saúde consiste em proporcionar aos povos os meios necessários para meIhorar sua saúde e exercer um maior controle sobrea mesma. Para alcançar um estado adequado de bem-estar físico, mental e social um indivíduo ou grupo deve ser capaz de identificar e realizar suas aspirações, de sati ffazer suas necessidades e de modificar ou adaptar-se ao meio ambiente. A saúde se percebe, pois, não como o objetivo, senão como a fonte de riqueza da vida cotidiana. Tratase, portanto, de um conceito positivo, que acentua os recursos sociais e pessoais assim como as atitudes. Por conseguinte, dado queo conceito de saúde como bem-estar transcendea idéia de formas de vida saudáveis, a promoção da saúde não concerneexclusi vamente ao setor saúde(WHO, 1986).

A ampliação da definição decausa dos problemas desaúde exigea incorporação denovos saberes, tradicional mente presentes em menor peso, no setor. As ciências sociais, o planejamento urbano, o planejamento estratégico, a geografia, a educação para a saúde, as ciências do meio ambiente, a comunicação social são algumas das disciplinas necessárias.

0 estabelecimento de ações intersetoriais deve permitir que, em cada área, surjam contribuições para a solução dos problemas de saúde. Esses problemas devem ser aqueles que emergem de discussões comunitárias. As prioridades poderão assim transformar-se em pautas positivas, promotoras de saúde. E a educação ea informação para a saúde passam a ser fundamentais nesse processo, na medida em que aumentam a consciência sanitária dos cidadãos e intensificam a participação dos mesmos na definição de prioridades. 0 desenvolvimento sustentável vêo ambiente como realidade e totalidades integradas, e vêo homem como partedas mesmas, que são vivenciadas segundo lugares singulares, segundo uma base territorial, segundo processos sociais vividos localmente. Assim épossível constituir-se um processo de reflexão coletiva sobre as condições de vida das comunidades e sobre como estas condições contribuem para o estado desaúdee para a qualidadedevida.

No processo de construção deambientes/ indivíduos/comunidades saudáveis são fundamentais conceitos como direitos de cidadania (lazer, moradia, trabalho, eqüidade, responsabilidade social pela saúde, participação, etc.). Essa dinâmica necessita de determinadas ferramentas técnicas, como 0 acesso à informação, à educação, à gestão dos recursos disponíveis, etc. É fundamental um esforço de participação no planejamento, na anál ise das relações sociais eas condições objetivas devida, reprodução esobrevivência. É preciso definir as possibilidades decada ator social e de todos para superar dificuldades, estabelecer compromissose pactuá-los politicamente. É bom lembrar que pacto pressupõe um diálogo entre atoresque se disponham a reconhecer a força uns dos outros, enão uma relação em quese busca o domínio ea imposição deum ator sobre o outro.

O segundo nível da atuação, tal como proposto no modelo da vigilância da saúde, refere-seà prevenção dos riscos deadoecimento. Estasanálises igualmente estão voltadas para entender o risco segundo os grupos sociais imersos em seu território. Informações hoje disponíveis na clínica ou na epidemiologia acerca dos principaisfatores de risco passariam assim a ser referenciadas à dinâmica dos grupos, dasfamílias, segundo as suas particularidades e segundo as dimen sões sanitária, ambiental eepidemiológica. A riqueza desse processo está em poder estabelecer novos elos causais esoluções que podem extrapolar 0 atendimento pontual efragmentado dos problemas desaúde. Dessa maneira os diversos grupos que atuam nas áreas ligadas à vigilância sanitária, epidemiológica eambiental, aos programas de saúde, que buscam a identificação eo controle de riscos devem procurar novas interfaces, trabal har deforma integrada. Infelizmenteainda se convive com equipes múltiplas, queatuam de forma vertical no plano central, agindo sobreum determinado vetor, ou sobre uma determinada doença infecciosa, sem uma visão abrangentee uma ação integral, segundo os problemas que afetam as comunidades. As ações programáticas necessitam ser repensadas no sentido de desenvolver ações quereduzam, concomitantemente, os múltiplos fatores relacionados ao adoecimento. M esmo considerando a importância da especialização e das distintas áreas do conhecimento técnico das equipes, é inadmissível que estas continuem trabalhando deforma isolada, cada qual voltada para a sua área de conhecimento. 0 que se constata, muitas vezes, éa total desarticulação entre elas. 
Grupostécnicos quecontrolam roedores, mosquitos, qualidade da água, alimentos, estabelecimentos, tuberculose, meningite, Aids, diarréia, sarampo, hanseníase, câncer, tabagismo, diabetes, hipertensão, DST, todos a atuar segundo suas próprias rotinas, sem nenhuma articulação ou planejamento, duplicando esegmentando uma realidade queéindivisível einter-relacionada. Vale ressaltar que, em alguns casos, essas equipes estão constituídas de maneira desigual ealgumas delas sequer atuam. D evido à ausência de recursos para financiá-las limitam-sea "contar casos". Dentremuitos exemplos desteproblema a superar pode sedestacar o caso da dengue. Seu ressurgimento éresultado da ocupação urbana mal planejada, da falta de saneamento, do aumento indiscriminado da produção deembalagens descartáveis e pneus, sem coleta e de destinos adequados, da degradação do meio ambiente, das condições de habitação, de hábitos de famílias e comunidades sobrea existência de focos e do modo de transmissão, da capacidade deadaptação do vetor às novas condições, etc. A destinação de, por vezes, vultosos recursos para a contratação de "mata-mosquitos" e "fumacês" em época de epidemias está diretamenterelacionado à ausência de recursos e ações sobre os riscos que as provocaram. Ao contrário, cada comunidade deveria estar sendo orientada e provida de meios parameIhorar as condições sanitárias e ambientais ea reduzir os riscos detransmissão. Para isso seria imprescindível que se promovessea consciência sanitária por meio da educação para a saúde, a intervenção sobreo lixo domiciliar, sobrea qualidade da água, do saneamento e das condições de moradia. Os agentes respon sáveis por essa atuação não poderiam, como ocorrehoje, estar exclusivamente voltados para um vetor, um mosquito, mas para as condições de risco social, sanitário, epidemiológico eambiental como um todo. Estariam assim contribuindo para a redução ef etiva de inúmeras outras doenças associadas e essas condições, como a leptospirose, as hepatites, a diarréia, etc.

0 terceiro nível de atuação refere-seà assistência propriamentedita. Q ue modelo assistencial poderia atender satisfatoriamente ao conjunto de pressupostos edesafios colocados pela integralidade? Como já foi abordado aqui, apesar de concebidos para esse fim, a existência de postose centros de saúdenão garantenecessariamenteessa atuação transformadora. São necessárias al gumas condições prévias para queos princípios da promoção eda prevenção passem a reger o funcionamento dos serviços desaúde. M aisuma vez a vincul ação das equipes ao território ea continuidade da atenção são imprescindíveis. Permitem o estabelecimento, a partir da identificação de problemas e da eleição de um conjunto de prioridades, do planejamento do trabalho em saúde. As equipes locais devem trabal har dessa forma, exercendo o papel de coordenação das ações de saúde em cada microárea do município. São esses os responsáveis pelo atendimento primário, pela decisão de seacessar os recursos disponíveis pelo atendimento primário, pela decisão de se acessar os recursos disponíveis no sistema municipal de saúde e de outras instâncias para atender aos problemas detectados. Contribuir para a organização da comunidade no esforço de melhorar as condições desaúde. A equipelocal é, portanto, responsável por todos os aspectos implicados com a saúdeetem por objetivo partilhar com a comunidadeos possíveis caminhose as decisões a respeito da promoção, da prevenção edo atendimento à saúde das famílias a el a referidas. Note-se ainda queo papel exercido por tais equipes evita queo próprio indivíduo, ou a família, tome para si, a responsabilidade de decidir a respeito da busca por serviços, atendimentos, exames, etc. É comum constatar que, por falta dessa equipelocal quea oriente, a população procura os serviços, em busca de atendimentos especializados, a partir de sua própria percepção de necessidades. A partir deum sinal esintoma, elegeum suposto especialista que possa resolver o problema. 0 re sultado dessecomportamento pode ser verificado na porta dos serviços desaúde, com filasintermináveis desdea madrugada.

Para que ocorra a mudança das práticas de saúde conforme exposto acima, énecessário também a transformação das relações de trabalho da própria equipe desaúde. U rgeuma nova forma de ol har o paciente, o colega de trabalho, e a si mesmo, como profissional de saúde. As equipes de saúde precisam oferecer mais do que a prestação deum serviço pura esimplesmente, entendido como a realização deatos formais. A formalidade ea burocratização da prática de saúde coíbe a satisfação profissional, além de provocar um estado de estagnação, em que o profissional tem consciência da inoperância do resultado final das ações realizadas, mas não sesenteresponsável por isso. Continua a realizá-las de forma mecânica, como não seincomodasse com a recorrência do adoecimento, fruto da permanência das determinações do mesmo. A criança volta toda semana com o mesmo quadro infeccioso ou respiratório, a mulher sequeixa do nervoso ou da dor de cabeça quenão tem solução. E assim sesucedem ospa- 
cientes, nos consultórios, com suas queixas recorrentes, diante das quais os profissionais se sentem impotentes, incapazes deagir deforma eficaz. É indispensável queo profissional tenha mais sensibilidade, escute 0 outro, saiba o que ele pensa, numa postura quenão seja distante eimpessoal. E tal vez esta postura o leve a expor, clara ediretamenteao paciente, as possibilidades eos limites da intervenção através do serviço de saúdeepasse a buscar, deforma criativa, novas possibilidades desuperação dos problemas identificados.

Em diversos países do mundo, como al nglaterra, Canadá, Espanha, H olanda, Cuba, M éxico, entreoutros, cabeao médico defamília o papel de prestar o primeiro atendimento e coordenar as ações de saú de para um conjunto específico efamílias deuma comunidade. No Brasil, desdea década de 1980 foi criado programa deresidência médica em medicina geral comunitária assim como a Sociedade Brasileira de M edicina Geral Comunitária. Apesar do movimento de mudanças curriculares voltado para a formação de médicos general istas, os impasses advindos da in definição deuma política de atenção básica no país resultaram em grande prejuízo ao ensino de pós-graduação, especialmente devido à baixa procura desse profissional pelos sistemas locais de saúde.

Essa tendência começou a ser revertida devido àiniciativa de municípios em implantar Programas deAgentes Comunitários de Saúde ede M edicina deFamília. Esses projetos, inicialmente isolados, se disseminaram e resgataram, para a sociedade e para os sistemas locais de saúde, a figura do médico da família e comunidade. Passouse então a questionar a estratégia anteriormente adotada, deorganização das unidades básicas de saúde, baseada no trabal ho de assistência médica por especialidades básicas. A partir de 1995 o M inistério da Saúde assumiu o compromisso deimplantar o Programa deSaúde da Família em todo o território nacional. O correu então a aceleração do processo deconstituição deequipes, tornando-seum consenso a importância do médico de família para compor eliderar as ações previstas na Atenção Básica à Saúde(UERJ, 1998).

Atualmente o Programa de Saúde da Família tornou-sea estratégia prioritária dereformulação do modelo assistencial da atenção básica, estando já implantadascerca de 10.000 equipes desaúdedafamíliano país. Essenúmero encontra-seem constanteevolução, dado o ritmo de crescimento do total de equipes no país. Estas são, geralmente, compostas por um médico, umaenfermeira, um auxiliar deenfermagem eentre 6 e 8 agentes comunitários desaúde. Recentementeforam incluídos na equipeprofissionais desaúdebucal.

No quadro 4 estão listadas as principais atribuições das equipes de saúdedafamília, segundo o M inistério daSaúde.

Como pode ser verificado, as atribuições das equipes guardam grandecoerência esintonia com os princípios da vigilânciada saúde. A saúdeda família pode, portanto, ser considerada o espaço das práticas deum novo modo de conceber o sistema de saúde. Essanova lógica deatuação não deveselimitar à saúde da família, mas, sim, disseminar-se por todos os serviços, desdeasunidades básicas atéas unidadeshospitalares. Outrosaparelhossociaispresentesem cadalocal devem estar também contribuindo para essa lógica assistencial. Deve-se buscar, nos programas de saúdecoletiva, o estabelecimento depropostas deação conjunta voltadas para solu-

\section{Quadro 4}

Atribuições das equipes de saúde da família segundo o M inistério da Saúde

- Conhecer a realidade das famílias (socioeconômica, psicológica, cultural, demográfica e epidemiológica)

- Identificar problemas de saúde e situações de risco

- Elaborar planos locais de saúde

- Valorizar o vínculo, a continuidade ea relação de confiança

- Executar ações de vigilância epidemiológica, ambiental esanitária

- D esenvolver ações voltadas para o controle da hanseníase, tuberculose, DST/Aids, doenças crônicas, ligadas ao trabalho e ao meio ambiente

- Resolver a maior parte dos problemas e garantir a referência

- Prestar assistência integral e promover a saúde através da educação para a saúde

- Desenvolver a auto-estima, o apoio mútuo, o autocuidado, a troca de experiências

- Promover ações intersetoriais e parcerias com organizações para a melhoria da qual idade de vida e do meio ambiente

- Incentivar a formação e a participação nos consel hos de Saúde.

Fonte: M S, Cadernos de A tenção Básica. Programa Saúde da Família, Brasília, 2000. 
cionar problemas relevantes eparticulares decada território, agregando contribuições de diversas áreastécnicas, contribuindo assim paraqueas equipeslocais possam estar capacitadas a tratar problemas deformaintegral.

A título deilustração podemos descrever um caso ocorrido no interior do Estado do Rio de Janeiro. Em determinada região começaram a surgir casos deinfecção de pele, em membrossuperiores, em homens adultos. Em um modelo convencional deassistênciaàsaúde, provavelmenteesses indivíduosteriam procurado um pronto atendimento deum serviço municipal esolucionado o problema através de antibióticos. Atéporque, segundo uma demandaespontânea dos indivíduos a locais distantes de sua moradia, não haveria porquesuspeitar, anão ser que o problema tomasseum vulto maior, deassociações

\section{Figura 1}

Seqüência após diagnóstico de infecção de pele por uma equipe de saúde da família

Infecção de pele
diagnóstico
etratamento

Associação causal investigação/cenário < ordenhadores

CO

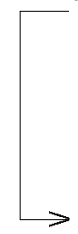

Impacto social e econômi-

Vigilância epidemiológica

e ambiental (Zoonosel

Cowpox)

Redução produção leiteira $<$

Desemprego

Vigilância sanitária

isolamento/eliminação gado contaminado

Informação e educação

para a saúde

identificação de focos

e erradicação causaisligadas ao território específico a queessesindivíduospertenciam. Não foi esta a dificuldadeda equipedesaúdeda família queatuava no local onde surgiram estescasos (Figura 1).

Tão logo surgiram as primeirasinfecções, osintegrantes da equipe de saúde da família imediatamenteperceberam arelação entrea ocorrênciados sintomas e o fato de esses indivíduos serem ordenhadores. A facilidadedeacesso ao território permitiu-Ihesidentificar queas vacas sofriam deumazoonose, na região das tetas. Parao homem, essa infecção não acarretaria maiores prejuízos, masteria gravesconseqüências paraa produção deleitee, por sua vez, para a sobrevivência das famílias. Caso aquele vírus não fosse controlado, toda a região sofreria gravemente, poishaveriaqueda da produção deleite em virtudedainfecção dosanimais.

As equipesforam capazes demobilizar a comunidadeeacionar setores ligados à vigilância sanitária, agricultura, epidemiologia, associaçõesegrupos deprodutores rurais eisolaram os animaisinfectados. Esteéum caso exemplar decomo as equipes de saúde devem trabalhar segundo o contexto social, econômico, sanitário, assistencial, a partir deum novo pensar eum novo agir em saúde. M ostra ainda quea equipenão tem necessariamente dedominar todo o conhecimento sobre as múltiplas ocorrências e agravos que acometem a comunidade, mas sim estar atenta às possíveis relações existentes entre o adoecer eavida cotidiana deseusintegrantes. Ao tomar parasi essa gestão da saúdelocal, a equipepodeacionar os diversos setores eespecialistas quecadacaso requer.

\section{Conclusão}

Estecapítulo buscou definir o Sistema Ú nico de Saúde como um processo em construção. Conceitos e concepções acerca das análises e práticas da saúde são frutos de construção coletiva, em que as vertentes técnica e política se entrelaçam. Se a Constituição brasilei ra possibilitou a conformação deum modelo para o sistema de saúde, outras medidas devem transformar o cotidiano das organizações e do trabal ho em saúde. N ovas formas de financiamento, novos instrumentos de análise da realidade, novos modos de estruturação de equipes que vão agir em saúde devem ser pensadas para se alcançarem princípios como eqüidade, integralidade, participação da comunidade. Se por um lado, criaram-se diversos espaços de pensamento e de práticas inovadoras, por outro, assiste-se a tentativas, às vezes inconfessáveis, de terceiri- 
zação e privatização da rede pública, do avanço da cobertura dos planos de saúde privados, da idéia de atenção básica como um pacote mínimo de ações vol tadas para a assistência aos pobres. Evidentemente que se buscou demonstrar a viabilidade de se alcançar um Sistema Ú nico de Saúde cal cado na resolutividade de problemas de saúde como um bem público. Especialmente afirma-se aqui a factibilidade de se enfrentarem os problemas de saúde vividos pela sociedade brasileira como uma totalidade social, ambiental, sanitária, epidemiológica eassistencial. Essas idéias e utopias foram vividas, em outras dimensões e circunstâncias históricas, por muitos dos que nos antecederam no serviço público de saúde. Entre eles, podemos citar Osvaldo Cruz, Miguel Couto, Afrânio Peixoto, Carlos Chagas, J. P. Fontenelle, Carlos Gentille de M elo, Cecília Donnângelo, David Capistrano.

$N$ ada do que se discute no âmbito da saúde brasileira continua mais atual do que o desafio que se coloca para a presente e as futuras gerações: tornar concreto, no quotidiano da vida dos cidadãos, os princípios que motivaram a Reforma Sanitária e o Sistema Ú nico de Saúde. Finalizamos este capítulo com o esquema extraído de documento da 11a Conferencia Nacional de Saúde, ocorrida em dezembro de 2000. Dele conclui-se que perseguir o que parece ser óbvio pode ser mais difícil do que se imagina (Figura 2).

Figura 1

Aspectos conceituais, princípios e características do SUS, 11ạ CN S/M S, 2001

\begin{tabular}{|l|l|}
\hline Reforma & Proposta para a democratização do país \\
\cline { 2 - 3 } &
\end{tabular}

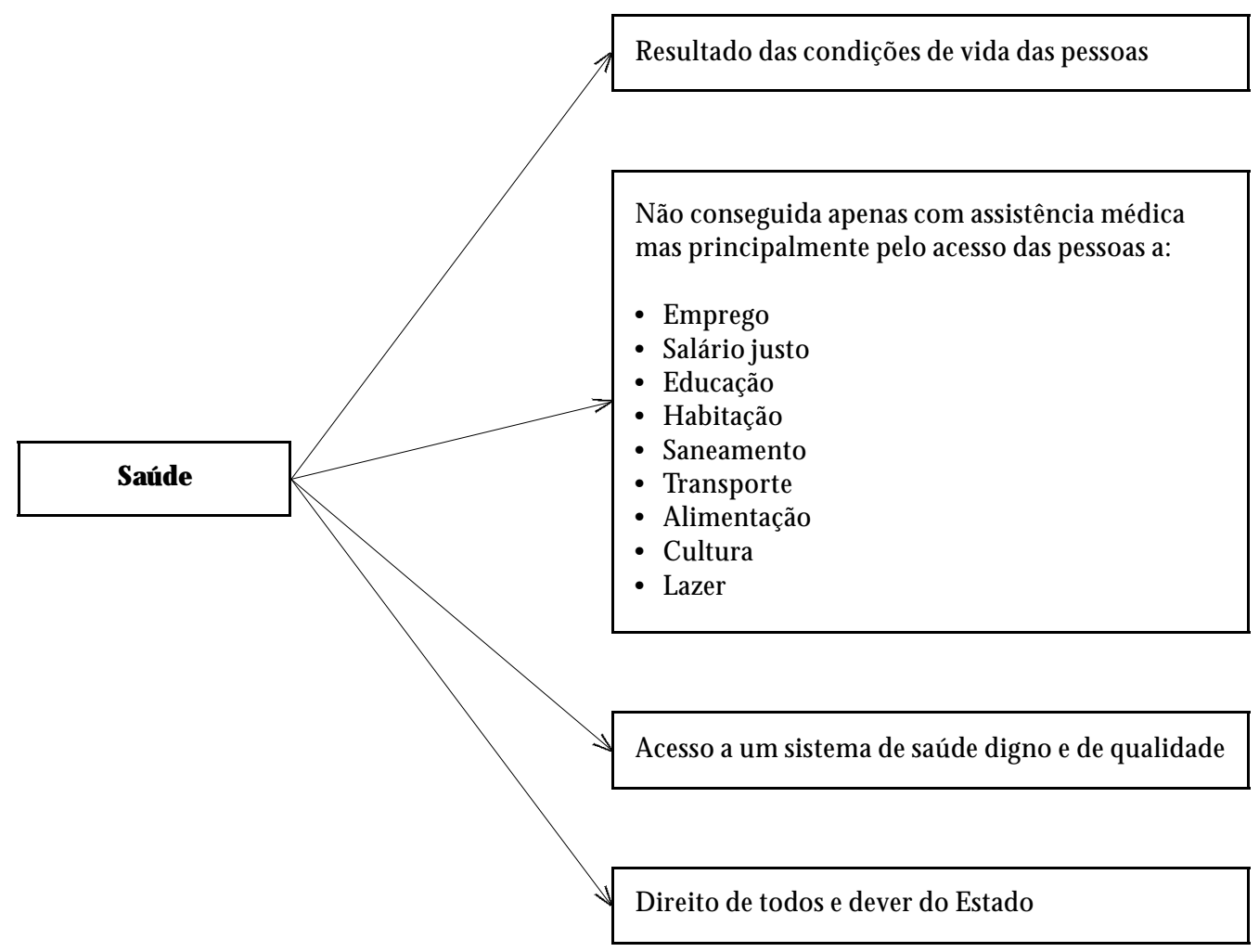




\section{Referências bibliográficas}

Brasil 1988. Constituição da República Federativa do Brasil. Cap. II, Seção II, Art. 198.

Contandriopoulos AP 1995. Reformar o sistema de saúde: uma utopia para sair de um status quo inaceitável. Saúde em Debate 49-50: 53-64, 1995/1996.

Elias P 1996. Saúde no Brasil. Cortez-Cedec, São Paulo.

Franco TB, Bueno WS \& M erhy EE 1997. 0 acolhimento e os processos de trabalho em saúde: o caso de Betim, M G. (Mimeo).

Giovanella $L$ et al. 2000. Integralidade da atenção em sistemas municipais de saúde: metodologia de avaliação e interven ção. Relatório de Pesquisa, Rio deJaneiro. EN SP/Fiocruz, Rio de Janeiro. M imeo.

Labra \& Buss 1995. Sistemas de saúde. Continuidades e mudanças. Hucitec, São Paulo.

M erhy EE 1997. Crise do modo de se produzir saúde: uma discussão do modelo assistencial e o trabalho médico no Brasil. (M imeo).
M inistério da Saúde 2001. Regionalização da Assistência à Saúde: aprofundando a descentralização com eqüidade no acesso. Norma O peracional da Assistência à Saúde N OAS-SUS 01/01. Brasília.

Sala A 1993. A avaliação de programas de saúde. Programação em Saúde H oje. Hucitec, São Paulo.

Teixeira CF, Paim JS \& Vilasbôas AL 1998. SUS, modelos assistenciais e vigilância da saúde. Informe Epidemiológico do SU S, ano VII, no. 2, abril/jun.

UERJ 1998. Reforma em saúde no Brasil. Programa de Saúde da Família. Informe final. Série Estudos de SaúdeColetiva.

Artigo apresentado em 17/12/2002

Aprovado em 20/1/2003

Versão final apresentada em 10/4/2003 